\title{
Dehydration and Cognition in Geriatrics: A Hydromolecular Hypothesis
}

\author{
Adonis Sfera ${ }^{1,2 *}$, Michael Cummings ${ }^{2 *}$ and Carolina Osorio ${ }^{1}$ \\ ${ }^{1}$ Department of Psychiatry, Loma Linda University, Loma Linda, USA, ${ }^{2}$ Patton State Hospital, Patton, USA
}

Dehydration is one of the ten most frequent diagnoses responsible for the hospital admission of elderly in the United States. It is associated with increased mortality, morbidity and an estimated cost of 1.14 billion per year (Xiao et al., 2004; Schlanger et al., 2010; Pretorius et al., 2013; Frangeskou et al., 2015). Older individuals are predisposed to dehydration encephalopathy as a result of decreased total body water (TBW) and diminished sensation of thirst. We hypothesize that thirst blunting in older individuals is the result of a defective microRNA-6842-3p failing to silence the expression of the vesicular GABA transporters (VGAT) and alpha 7 cholinergic nicotinic receptors in the subfornical organ (SFO) of the hypothalamus. We hypothesize further that resultant dehydration facilitates protein misfolding and aggregation, predisposing to neurocognitive disorders.

Edited by:

Megha Agrawal,

University of Illinois at Chicago, USA

Reviewed by:

Ravi C. Kalathur New York Structural Biology Center,

Enno Klussmann Max Delbrück Center for Molecular Medicine, Germany

*Correspondence: Adonis Sfera dr.sfera@gmail.com; Michael Cummings Michael.Cummings@DSH.ca.gov

Specialty section: This article was submitted to Molecular Diagnostics, a section of the journal Frontiers in Molecular Biosciences

Received: 28 January 2016 Accepted: 25 April 2016 Published: 12 May 2016

Citation: Sfera A, Cummings $M$ and Osorio C (2016) Dehydration and Cognition in Geriatrics: A Hydromolecular Hypothesis. Front. Mol. Biosci. 3:18. doi: 10.3389/fmolb.2016.00018
We completed a search of predicted microRNA targets, utilizing the public domain tool miRDB and found that microRNA-6842-3p modulates the SLC6A1 and CHRNA7 genes both of which were previously hypothesized to inhibit the thirst sensation by their action on SFO. The primary aim of this article is to answer two questions: Can prevention and correction of dehydration in elderly lower age-related cognitive deterioration? Can exosomal miR-6842 in the peripheral blood predict dehydration encephalopathy in elderly?

Keywords: dehydration, aquaporins, extracellular space, protein folding, protein conformational dynamics

\section{HYDRATION AND COGNITION}

Dehydration is one of the most common medical problems in seniors diagnosed in $6.7 \%$ of hospitalized patients over the age of 65 (Warren et al., 1994). It leads to poor outcomes and increased health care expenditures. Novel studies reveal that if not prevented or treated promptly, dehydration results in longer intensive care unit (ICU) stay, higher hospital readmission rates and placement in long term facilities (Xiao et al., 2004; Frangeskou et al., 2015). On the other hand, preventing dehydration not only reduces healthcare expenditures, but also improves outcomes and the elderly patients' quality of life.

Dehydration is a contributing factor for delirium, a neurobehavioral syndrome recently demonstrated to be a strong risk factor for dementia (Inouye, 1998; Davis et al., 2012). It is therefore crucial to recognize and diagnose dehydration quickly, however at the present time there are no specific biological markers for this condition. Clinical signs, plasma osmolality and urine markers have poor specificity in elderly (George and Rockwood, 2004). For this reason potential epigenetic markers such as microRNA-6842-3p obtained from peripheral blood exosomes may contribute not only to early diagnosis, but also to prevention of dehydration. 
Water is an essential body nutrient and its homeostasis is crucial for life. Early in the evolution, marine animals were surrounded by water, but survival on dry land required built-in, "portable" water (Warren et al., 1994). In humans, the muscle tissue is a genuine fluid reservoir, carrying over $80 \%$ of TBW (George and Rockwood, 2004).

The brain, in spite of being a highly lipophilic organ consists of $80 \%$ water (Tait et al., 2008). Most of the CNS intracellular water is stored in astrocytes. These cells are characterized by high aquaporin (AQP) expression which makes them four times more permeable to water than other brain cells, therefore true "brain cisterns" for times of water scarcity (Thrane et al., 2014). With the same token, because of their high AQP content, astrocytes are prone to pathological water retention and swelling. Novel studies demonstrate that astrocytes respond to peripheral dehydration by up-regulation of AQP-4 proteins on their end-feet processes probably in order to preserve water. For example, preclinical studies demonstrate that a hyperosmotic milieu induces AQP expression in astrocytes (Yang et al., 2013).

Overexpression of AQP-4 channels and augmented water intake transforms these cells into genuine "sponges" resulting in extracellular dehydration, extracellular space (ECS) hypovolemia. If severe enough this condition may turn into a medical emergency, dehydration encephalopathy or delirium.

The process of aging seems to undo the evolutionary advantage of "portable water" as elderly individuals are known to lose their fluid reservoirs by age-related decrease in both muscle mass and astrocyte density. For example, dehydration was demonstrated to accelerate the progression of $\mathrm{AD}$ which is also known to be associated with loss of astrocytes (Ogawa et al., 2011; Reyes-Haro et al., 2015; Rodríguez-Arellano et al., 2016).

It is well known that aging is associated with reduced acetylcholine (ACh) in the brain, but it is perhaps less emphasized that aging contributes to down-regulation of alpha7 nicotinic acetylcholine receptors (alpha7nAChR) (Utsugisawa et al., 1999; Akhmedov et al., 2013), rendering the CNS less responsive to ACh. This is significant for the sensation of thirst which is physiologically activated by ACh. Lower cholinergic activation predisposes to inflammation which is also involved in cognitive impairment. We discussed inflammation in the aging brain elsewhere and this subject will not be brought here (Sfera and Osorio, 2014). The alpha7nAChR are encoded by CHRNA7 gene which is subject to microRNA epigenetic regulation, including miR-6842.

Concerning the relationship between dehydration and impaired cognition nutrition studies demonstrate that a loss of only $1-2 \%$ of TBW may result in impaired cognitive performance; in elderly this percentage was shown to be even lower (Han and Wilber, 2013; Riebl and Davy, 2013). Furthermore, the link between hydration and cognition can be demonstrated by the neurocognitive disorders associated with up-regulation of AQP-4 expression primarily on asyrocytic end-feet (Table 1).

Novel studies demonstrate that both dehydration and aging were associated with AQP-4 up-regulation, therefore it should not come as a surprise that aging and water loss go hand in hand (Trinh-Trang-Tan et al., 2003). Interestingly, several amyloid-binding, neuroprotective compounds were demonstrated to down-regulate AQP-4 expression, further demonstrating the role of water in amyloid pathology (Table 2).

In addition, neuroimaging studies in dehydrated elderly, show decrease in gray and white matter volume (Streitbürger et al., 2012). However, it is important to keep in mind that most brain volumetric studies rely on diffusion tensor imaging (DTI) which detects water anisotropy and is therefore highly dependent on the brain fluid dynamics (Meng et al., 2004; Nakamura et al., 2014).

\section{WATER AND PROTEIN MISFOLDING DISORDERS}

Misfolded protein aggregates were shown to be involved in many human diseases, including neurocognitive disorders and diabetes type 2, but in spite of the increasing prevalence of these conditions, the reason proteins misfold is not completely understood.

Water has been known to play a major role in protein conformational dynamics (Lemieux, 1996; Phillips, 2002; Zhao et al., 2013). In order to become biologically active newly transcribed proteins must fold along specific axes like paper in the ancient Japanese art of origami (Collet, 2011; Chong

TABLE 1 | Disorders associated with cognitive deficit and AQP-4 up-regulation.

\begin{tabular}{ll}
\hline AQP-4/Cognitive deficit disorders & References \\
\hline Cerebral amyloid angiopathy & $\begin{array}{l}\text { Foglio and Fabrizio, 2010; } \\
\text { Moftakhar et al., 2010 }\end{array}$ \\
Alzheimer's disease & Nagelhus and Ottersen, 2013; \\
& Lan et al., 2015 \\
Parkinson's disease & Subburaman and Vanisree, 2011; \\
& Zhang et al., 2016 \\
Multiple sclerosis & Tanaka et al., 2007 \\
Neuromyelitis optica & Saji et al., 2013; Zhang et al., \\
& 2015 \\
Traumatic brain injury & Hu et al., 2005 \\
Cerebral ischemia & Zador et al., 2009 \\
Epilepsy & Binder et al., 2012; Alvestad \\
& et al., 2013 \\
HIV encephalitis & St. Hillaire et al., 2005 \\
Progressive multifocal leukoencephalopathy & Aoki-Yoshino et al., 2005; \\
& Florence et al., 2012
\end{tabular}

TABLE 2 | Neuroprotective compounds associated with AQP-4 down-regulation.

\begin{tabular}{ll}
\hline AQP-4 down-regulation & References \\
\hline Rapamycin & Guo et al., 2014 \\
Erythropoietin & Gunnarson et al., 2009; McCook et al., 2012 \\
Curcumin & Laird et al., 2010; Wang et al., 2015 \\
Purines & Morelli et al., 2010; Lee et al., 2013 \\
Progesteron & He et al., 2014 \\
Melatonin & Dehghan et al., 2013; Lin et al., 2013; \\
& Bhattacharyaa et al., 2014
\end{tabular}


and Ham, 2015). Recently it was demonstrated that water plays a crucial role in this process as it forms hydrogen bonds with the amino acid chains, facilitating their collapse into three dimensional molecular structures. In the presence of water, folding occurs almost instantly (140 ns), resulting in biologically active molecules available for chemical reactions at the opportune time (Sen and Voorheis, 2014; Vajda and Perczel, 2014). In the absence of hydration the folding process is significantly slower and the biomolecules may miss the timing of their reactions. This results in molecular overcrowding which predisposes to misfolding (Gregersen et al., 2006; Stoppini et al., 2009). Indeed, it was hypothesized by others that biomolecular crowding relative to the fluid volume is inductive of misfolding and aggregation (Tokuriki et al., 2004; Yerbury et al., 2005).

Novel studies in protein conformational dynamics demonstrate that both protein misfolding, their repair and removal can take place in the intra and the extracellular compartment. The chance of protein misfolding is higher in the extracellular space (ECS) which is a rougher environment exposing these biomolecules to a higher degree of shear and tear (Ker and Chen, 1998; Genereux and Wiseman, 2015). For this reason, we focus our study on the ECS where hypovolemia may facilitate protein misfolding and aggregation.

It was hypothesized that adequate water circulation via aquaporin $(\mathrm{AQP})$ channels is essential for clearing beta amyloid and for preventing its build-up characteristic for Alzheimer's disease (AD) (Figure 1). The glymphatic system paradigm suggests that insufficient amyloid clearance and its subsequent aggregation is the result of impaired water movement (Xie et al., 2013). This model, however pays less attention as to why proteins misfold in the first place.

The hydromolecular hypothesis is therefore complementary to the glymphatic model, but also differs from it by elevating water from an inert medium to an active participant in cognition (via protein folding) (Levy and Onuchic, 2006). This hypothesis raises another interesting question: do proteins participate in information processing directly?

Novel studies in neuroscience demonstrate that proteins participate in cognition by their ability to access logic gates, the elementary building blocks of digital circuits (Qi et al., 2013). These molecules are endowed with abilities to adaptively change their shapes in Transformers-like fashion, assembling and disassembling in response to electronic signals or electromagnetic fields (Kidd et al., 2009; Ausländer et al., 2012). For example, proteins were shown to assemble in the neuronal post-synaptic membrane into heteroreceptor complexes which may engender memory "bar codes" (Fuxe et al., 2007; Chen et al., 2012). Calcium-calmodulin-dependent kinase III, a component of neuronal microtubules, was hypothesized to store long term memory by reorganizing its spatial structure in response to synaptic activity (Smythies, 2015). Interestingly, water plays a

\section{ASTROCYTE AND THE EXTRACELLULAR SPACE (ECS)}

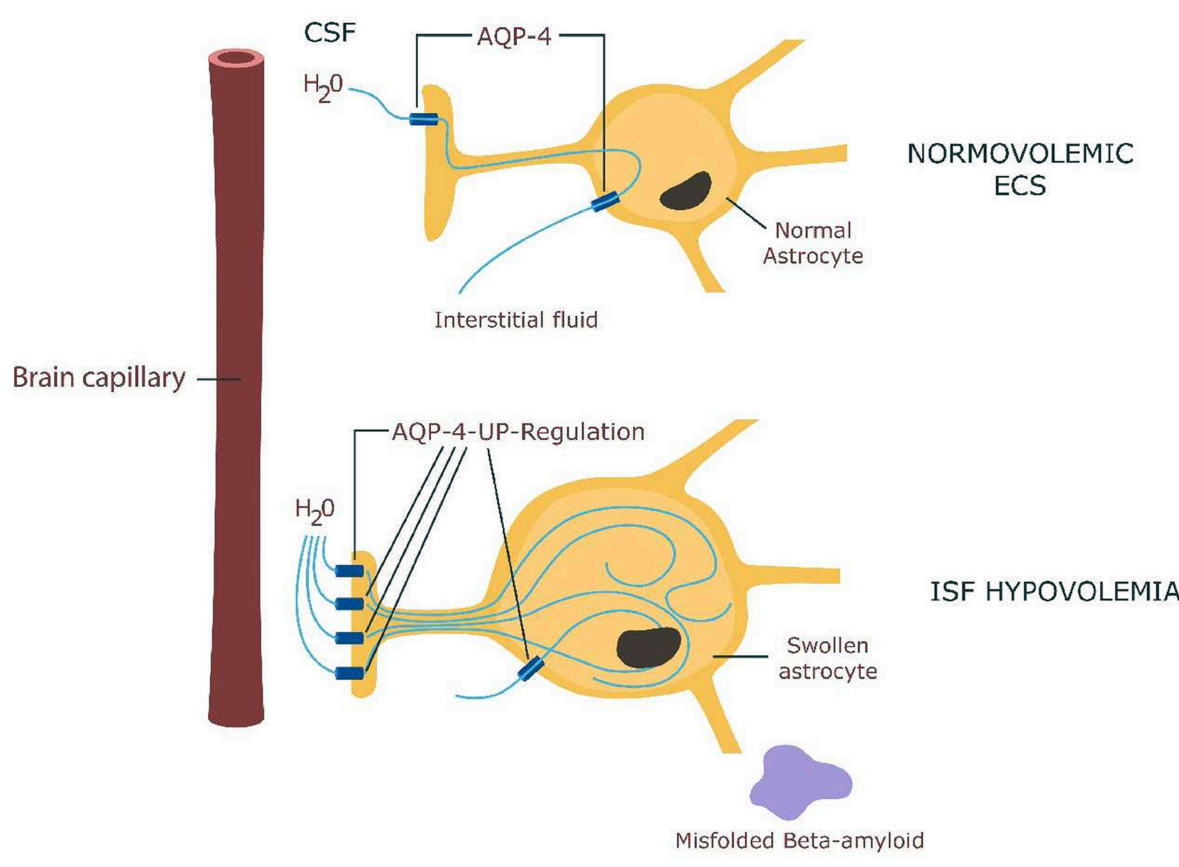

FIGURE 1 | Astrocyte swelling as a result of AQP-4 channels up-regulation with interstitial fluid hypovolemia and beta-amyloid misfolding. 
major role in this model. Several studies revealed that dendritic spine biomolecules may play a crucial role in associative memory as they endow the neural circuits with Boolean logic (Craddock et al., 2012; De Ronde et al., 2012; Qi et al., 2013). Furthermore, proteins are endowed with Lego-like abilities to interlink, engendering large intra and extracellular biomolecular networks with hypothesized roles in cognition (Chen et al., 2012; Mancuso et al., 2014). In light of this data we believe that alteration of the normal protein conformation may impair cognition directly, rather than indirectly by damaging synapses and neurons which is the traditional view.

\section{EPIGENOMIC REGULATION OF THE SUBFORNICAL ORGAN (SFO)}

Elderly individuals are prone to dehydration as a result of blunted thirst sensation and loss of TBW as discussed above (Cowen et al., 2013; Hooper et al., 2014). Recent preclinical data reveal that the subfornical organ (SFO) of the hypothalamus functions as a "thirst center" in the mammalian brain, regulating the basic instinct of water intake (Oka et al., 2015). Since the SFO lacks a blood-brain-barrier (BBB) it may be well positioned to detect peripheral dehydration and respond to it by increasing the sensation of thirst lowering water output. The SFO contains sensitive osmoreceptors which convert peripheral changes in osmolality into an excitatory neuronal signal, triggering both the sensation of thirst and the release of arginine vasopressin (AVP) by the posterior pituitary (Azizi et al., 2008).

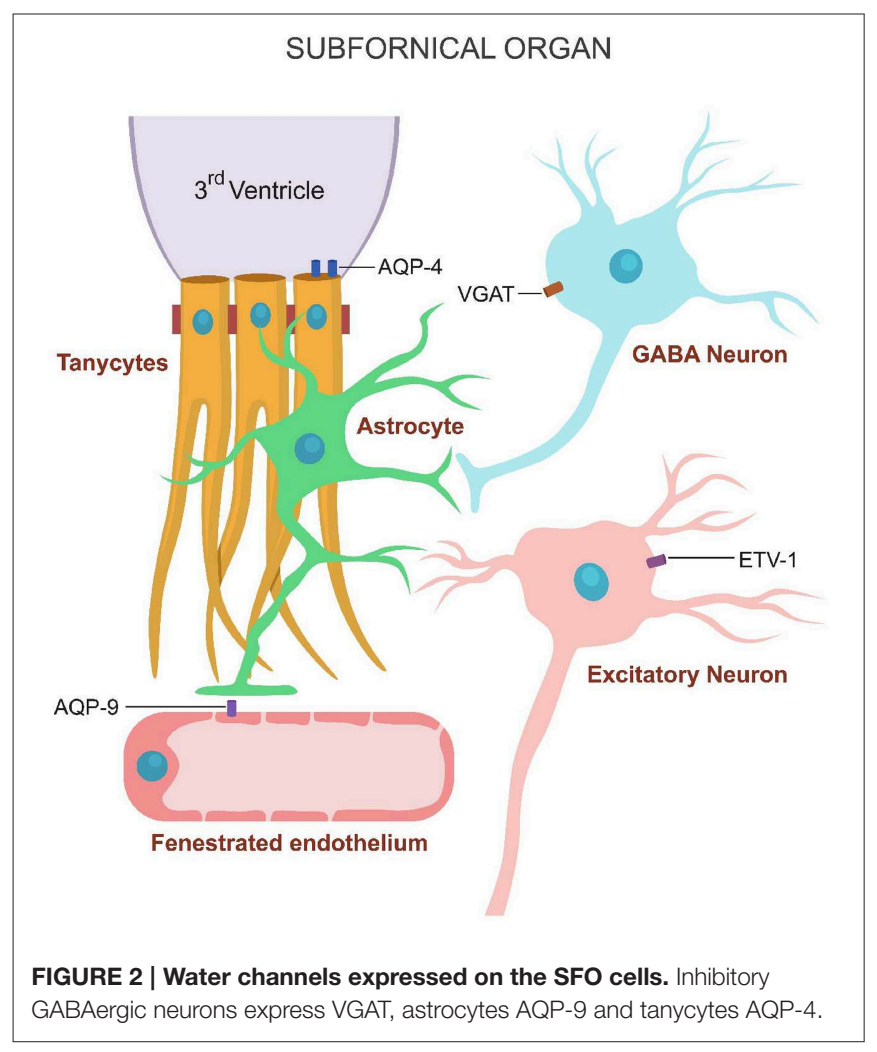

It was recently demonstrated that the SFO contains both excitatory and inhibitory neurons which can be activated by the ECS water volume and osmolality (Oka et al., 2015). ECS hypovolemia activates the SFO excitatory neurons (which express ETV-1 transcription factor), triggering thirst. ECS normovolemia, on the other hand activates the SFO inhibitory neurons (which express the vesicular GABA transporter (VGAT)], inhibiting the sensation of thirst.

These genetically distinct neuronal groups may explain both dehydration and psychotic polydipsia. For example, excessive activation of excitatory, or failure to activate inhibitory SFO neurons may result in psychotic polydipsia. The opposite may be true in dehydration.

Several prior studies revealed that the sensation of thirst may also be activated by the stimulation of SFO neuronal cholinergic receptors. The SFO neurons express both nicotinic and muscarinic cholinergic receptors, while the SFO astrocytes express only alpha 7- nAChRs (Honda et al., 2003; Tanaka, 2003; Ono et al., 2008). Age-related paucity of these receptors interferes with ACh activation of the thirst sensation. The glial water channels consist of AQP-9 expressed by astrocytes and AQP-4 expressed by tanycytes (Figure 2).

In addition to decreasing the expression of alpha $7 \mathrm{nAChRs}$, the aging process was documented to augment the expression of AQP channels on astrocytic end-feet as part of an age-related senescence-associated secretory phenotype (SASP). SASP is characterized by low grade inflammation, increased accumulation of misfolded protein aggregates and astrocyte swelling induced by AQP up-regulation (Picciotto and Zoli, 2002; Salminen et al., 2011; Akhmedov et al., 2013).

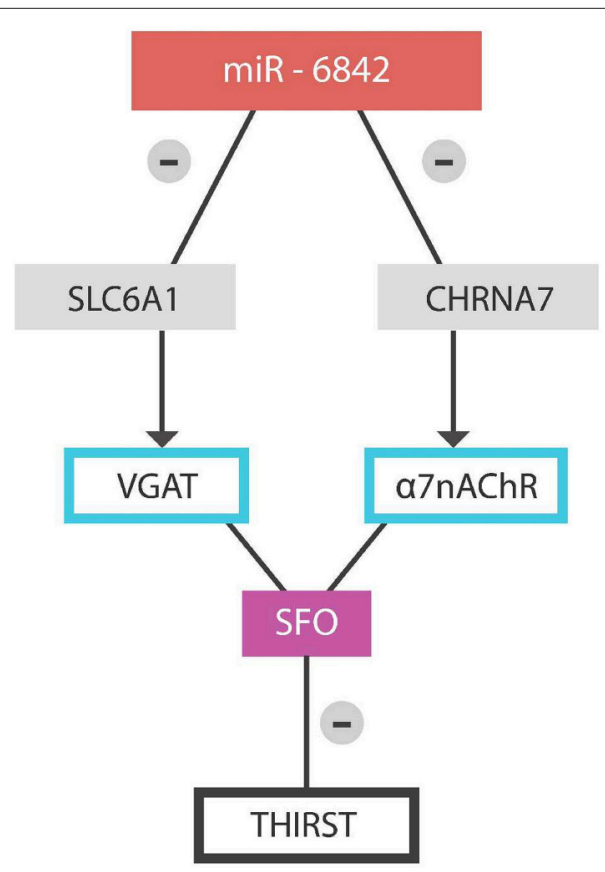

FIGURE 3 | Physiologically, microRNA-6842 silences SLC6A1 and CHRNA7 genes, activating the sensation of thirst. 
Peripheral dehydration was demonstrated to alter the expression of several SFO- related genes (Hindmarch et al., 2008). One of these genes is SLC6A1 which expresses VGAT on the cellular membranes of the SFO inhibitory neurons.

Method: we conducted a search of miRDB, a public online database for microRNA target prediction and functional annotations. The targets in miRDB are predicted by the bioinformatics tool, MirTarget. MirTarget was developed by analyzing thousands of miRNA-target interactions from highthroughput sequencing experiments. We searched the human database for the genes of interest SLC 32A1 and CHRNA 7, coding for VGAT and alpha 7 nicotinic cholinergic receptors respectively. We conducted a separate search for each of the two genes by utilizing the gene symbol SLC 32A1 and CHRNA 7. The results revealed that 131 microRNAs modulate the SLC 32A1 gene and 57 microRNAs the CHRNA 7 gene. Analyzing this data, miR by miR we found one common microRNA modulating both genes, the miR-6842 (Figure 3).

A dysfunctional miR-6842 may fail to silence the SLC6A1 gene, preventing inhibition of the SFO GABAergic neurons with

\section{REFERENCES}

Akhmedov, K., Rizzo, V., Kadakkuzha, B. M., Carter, C. J., Magoski, N. S., Capo, T. R., et al. (2013). Decreased response to acetylcholine during aging of Aplysia neuron R15. PLoS ONE 8:e84793. doi: 10.1371/journal.pone.0084793

Alvestad, S., Hammer, J., Hoddevik, E. H., Skare, Ø., Sonnewald, U., AmiryMoghaddam, M., et al. (2013). Mislocalization of AQP4 precedes chronic seizures in the kainate model of temporal lobe epilepsy. Epilepsy Res. 105, 30-41. doi: 10.1016/j.eplepsyres.2013.01.006

Aoki-Yoshino, K., Uchihara, T., Duyckaerts, C., Nakamura, A., Hauw, J. J., and Wakayama, Y. (2005). Enhanced expression of aquaporin 4 in human brain with inflammatory diseases. Acta Neuropathol. 110, 281-288. doi: 10.1007/s00401-005-1052-2

Ausländer, S., Ausländer, D., Müller, M., Wieland, M., and Fussenegger, M. (2012). Programmable single-cell mammalian biocomputers. Nature 487, 123-127. doi: $10.1038 /$ nature 11149

Azizi, M., Iturrioz, X., Blanchard, A., Peyrard, S., De Mota, N., Chartrel, N., et al. (2008). Reciprocal regulation of plasma apelin and vasopressin by osmotic stimuli. J. Am. Soc. Nephrol. 19, 1015-1024. doi: 10.1681/ASN.2007070816

Bhattacharyaa, P., Kumar, A., Paulb, P. S., and Patnaikb, R. (2014). Melatonin renders neuroprotection by protein kinase $\mathrm{C}$ mediated aquaporin- 4 inhibition in animal model of focal cerebral ischemia. Life Sci. 100, 97-109. doi: 10.1016/j.lfs.2014.01.085

Binder, D. K., Nagelhus, E. A., and Ottersen, O.P. (2012). Aquaporin-4 and epilepsy. Glia 60, 1203-1214. doi: 10.1002/glia.22317

Chen, Y.-S., Hon, M.-Y., and Huang, G. S. (2012). A protein transistor made of an antibody molecule and two gold nanoparticles. Nat. Nanotechnol. 7, 197-203. doi: $10.1038 /$ nnano.2012.7

Chong, S. H., and Ham, S. (2015). Distinct role of hydration water in protein misfolding and aggregation revealed by fluctuating thermodynamics analysis. Acc. Chem. Res. 48, 956-965. doi: 10.1021/acs.accounts.5b00032

Collet, O. (2011). How does the first water shell fold proteins so fast? J. Chem. Phys. 134, 085107. doi: 10.1063/1.3554731

Cowen, L. E., Hodak, S. P., and Verbalis, J. G. (2013). Age-associated abnormalities of water homeostasis. Endocrinol. Metab. Clin. North Am. 42, 349-370. doi: 10.1016/j.ecl.2013.02.005

Craddock, T. J. A., Tuszynski, J. A., and Hameroff, S. (2012). Cytoskeletal signaling: is memory encoded in microtubule lattices by CaMKII phosphorylation? PLoS Comput. Biol. 8:e1002421. doi: 10.1371/journal.pcbi.1002421 resultant thirst blocking. The same is achieved via failure to inhibit the CHRNA-7 gene, thus preventing ACh-induced thirst.

\section{CONCLUSIONS}

The hydromolecular hypothesis endeavors to explain the relationship between dehydration and decreased cognition in elderly as resulting from protein misfolding and aggregation in the context of low interstitial fluid volume (ECS hypovolemia). Defective proteins may affect cognition either directly via impaired information processing in the brain biomolecular networks, or indirectly via neuronal and synaptic damage, or both.

MicroRNA-6842 may constitute a biological marker with predictive value for dehydration encephalopathy in elderly as it regulates two genes involved in the sensation of thirst.

\section{AUTHOR CONTRIBUTIONS}

All authors listed, have made substantial, direct and intellectual contribution to the work, and approved it for publication.

Davis, D. H. J., Terrera, G. M., Tuomo, P., Sulkava, R., MacLullich, A. M. J., and Carol, B. (2012). Delirium is a strong risk factor for dementia in the oldest-old: a population-based cohort study. Brain 135, 2809-2816. doi: 10.1093/brain/aws190

Dehghan, F., Khaksari Hadad, M., Asadikram, G., Najafipour, H., and Shahrokhi, N. (2013). Effect of melatonin on intracranial pressure and brain edema following traumatic brain injury: role of oxidative stresses. Arch. Med. Res. 44, 251-258. doi: 10.1016/j.arcmed.2013.04.002

De Ronde, W., Rein ten Wolde, P., and Mugler, A. (2012). Protein logic: a statistical mechanical study of signal integration at the single-molecule level. Biophys. J. 103, 1097-1107. doi: 10.1016/j.bpj.2012.07.040

Florence, C. M., Baillie, L. D., and Mulligan, S. J. (2012). Dynamic volume changes in astrocytes are an intrinsic phenomenon mediated by bicarbonate ion flux. PLoS ONE 7:e51124. doi: 10.1371/journal.pone.0051124

Foglio, E., and Fabrizio, R. E. (2010). Aquaporins and neurodegenerative diseases. Curr. Neuropharmacol. 8, 112-121. doi: 10.2174/157015910791233150

Frangeskou, M., Lopez-Valcarcel, B., and Serra-Majem, L. (2015). Dehydration in the elderly: a review focused on economic burden. J. Nutr. Health Aging. 19, 619-627. doi: 10.1007/s12603-015-0491-2

Fuxe, K., Canals, M., Torvinen, M., Marcellino, D., Terasmaa, A., Genedani, S., et al. (2007). Intramembrane receptor-receptor interactions: a novel principle in molecular medicine. J. Neural Transm. 114, 49-75. doi: 10.1007/s00702-0060589-0

Genereux, J. C., and Wiseman, R. L. (2015). Regulating extracellular proteostasis capacity through the unfolded protein response. Prion 9, 10-21. doi: $10.1080 / 19336896.2015 .1011887$

George, J., and Rockwood, K. (2004). Dehydration and delirium-not a simple relationship. J. Gerontol. A Biol. Sci. Med. Sci. 59, 811-812. doi: 10.1093/gerona/59.8.M811

Gregersen, N., Bross, P., Vang, S., and Christensen, J. H. (2006). Protein misfolding and human disease. Annu. Rev. Genomics Hum. Genet. 7, 103-124. doi: 10.1146/annurev.genom.7.080505.115737

Gunnarson, E., Song, Y., Kowalewski, J. M., Brismar, H., Brines, M., Cerami, A., et al. (2009). Erythropoietin modulation of astrocyte water permeability as a component of neuroprotection. Proc. Natl. Acad. Sci. U.S.A. 106, 1602-1607. doi: 10.1073/pnas.0812708106

Guo, W., Feng, G., Miao, Y., Liu, G., and Xu, C. (2014). Rapamycin alleviates brain edema after focal cerebral ischemia reperfusion in rats. Immunopharmacol. Immunotoxicol. 36, 211-223. doi: 10.3109/08923973.2014.913616 
Han, J. H., and Wilber, S. T. (2013). Altered mental status in older emergency department patients. Clin. Geriatr. Med. 29, 101-136. doi: 10.1016/j.cger.2012.09.005

He, L., Zhang, X., Wei, X., and Li, Y. (2014). Progesterone attenuates aquaporin-4 expression in an astrocyte model of ischemia/reperfusion. Neurochem. Res. 39, 2251-2261. doi: 10.1007/s11064-014-1427-7

Hindmarch, C., Fry, M., Yao, S. T., Smith, P. M., Murphy, D., and Ferguson, A. V. (2008). Microarray analysis of the transcriptome of the subfornical organ in the rat: regulation by fluid and food deprivation. Am. J. Physiol. Regul. Integr. Comp. Physiol. 295, R1914-R1920. doi: 10.1152/ajpregu.90560.2008

Honda, E., Ono, K., Toyono, T., Kawano, H., Masuko, S., and Inenaga, K. (2003). Activation of muscarinic receptors in rat subfornical organ neurones. J. Neuroendocrinol. 15, 770-777. doi: 10.1046/j.1365-2826.2003.01057.x

Hooper, L., Bunn, D., Jimoh, F. O., and Fairweather-Tait, S. J. (2014). Water-loss dehydration and aging. Mech. Ageing Dev. 136-137, 50-58. doi: 10.1016/j.mad.2013.11.009

Hu, H., Yao, H. T., Zhang, W. P., Zhang, L., Ding, W., Zhang, S. H., et al. (2005). Increased expression of aquaporin- 4 in human traumatic brain injury and brain tumors. J. Zhejiang Univ. Sci. B. 6, 33-37. doi: 10.1631/jzus.2005.B0033

Inouye, S. K. (1998). Delirium in hospitalized older patients. Clin. Geriatr. Med. $14,754-764$.

Ker, Y. C., and Chen, R. H. (1998). Shear-induced conformational changes and gelation of soy protein isolate suspensions. Food Sci. Technol. 31, 107-113. doi: 10.1006/fstl.1997.0306

Kidd, B. A., Baker, D., and Thomas, W. E. (2009). Computation of conformational coupling in allosteric proteins. PLoS Comput. Biol. 5:e1000484. doi: 10.1371/ journal.pcbi.1000484

Laird, M. D., Sukumari-Ramesh, S., Swift, A. E., Meiler, S. E., Vender, J. R., and Dhandapani, K. M. (2010). Curcumin attenuates cerebral edema following traumatic brain injury in mice: a possible role for aquaporin-4? J. Neurochem. 113, 637-648. doi: 10.1111/j.1471-4159.2010.06630.x

Lan, Y. L., Zhao, J., Ma, T., and Li, S. (2015). The potential roles of aquaporin 4 in alzheimer's disease. Mol. Neurobiol. doi: 10.1007/s12035-015-9446-1. [Epub ahead of print].

Lee, M. R., Ruby, C. L., Hinton, D. J., Choi, S., Adams, C. A., Young Kang, N., et al. (2013). Striatal adenosine signaling regulates EAAT2 and astrocytic AQP4 expression and alcohol drinking in mice. Neuropsychopharmacology 38, 437-445. doi: 10.1038/npp.2012.198

Lemieux, R. M. (1996). How water provides the impetus for molecular recognition in aqueous solution. Acc. Chem. Res. 29, 373-380. doi: 10.1021/ar9600087

Levy, Y., and Onuchic, J. N. (2006). Water mediation in protein folding and molecular recognition. Annu. Rev. Biophys. Biomol. Struct. 35, 389-415. doi: 10.1146/annurev.biophys.35.040405.102134

Lin, L., Huang, Q.-X., Yang, S.-S., Chu, J., Wang, J.-Z., and Tian, Q. (2013). Melatonin in Alzheimer's disease. Int. J. Mol. Sci. 14, 14575-14593. doi: 10.3390/ijms140714575

Mancuso, J. J., Cheng, J., Yin, Z., Gilliam, J. C., Xia, X., Li, X., et al. (2014). Integration of multiscale dendritic spine structure and function data into systems biology models. Front. Neuroanat. 8:130. doi: 10.3389/fnana.2014.00130

McCook, O., Georgieff, M., Scheuerle, A., Möller, P., Thiemermann, C., and Radermacher, P. (2012). Erythropoietin in the critically ill: do we ask the right questions? Crit. Care 16, 319. doi: 10.1186/cc11430

Meng, S., Qiao, M., Lin, L., Del Bigio, M. R., Tomanek, B., and Tuor, U. I. (2004). Correspondence of AQP4 expression and hypoxic-ischaemic brain oedema monitored by magnetic resonance imaging in the immature and juvenile rat. Eur. J. Neurosci. 19, 2261-2269. doi: 10.1111/j.0953-816X.2004.03315.x

Moftakhar, P., Lynch, M. D., Pomakian, J. L., and Vinters, H. V. (2010). Aquaporin expression in the brains of patients with or without cerebral amyloid angiopathy. J. Neuropathol. Exp. Neurol. 69, 1201-1209. doi: 10.1097/NEN.0b013e3181fd252c

Morelli, M., Carta, A. R., Kachroo, A., and Schwarzschild, M. A. (2010). Pathophysiological roles for purines: adenosine, caffeine and urate. Prog. Brain Res. 183, 183-208. doi: 10.1016/S0079-6123(10)83010-9

Nagelhus, E. A., and Ottersen, O. P. (2013). Physiological roles of aquaporin-4 in brain. Physiol. Rev. 93, 1543-1562. doi: 10.1152/physrev.00011.2013

Nakamura, K., Brown, R. A., Araujo, D., Narayanan, S., and Arnold, D. L. (2014). Correlation between brain volume change and $\mathrm{T} 2$ relaxation time induced by dehydration and rehydration: implications for monitoring atrophy in clinical studies. Neuroimage 6, 166-170. doi: 10.1016/j.nicl.2014.08.014

Ogawa, E., Sakakibara, R., Endo, K., Tateno, F., Matsuzawa, Y., Hosoe, N., et al. (2011). Incidence of dehydration encephalopathy among patients with disturbed consciousness at a hospital emergency unit. Clin. Prac. 1:e9. doi: 10.4081/cp.2011.e9

Oka, Y., Ye, M., and Zuker, C. S. (2015). Thirst driving and suppressing signals encoded by distinct neural populations in the brain. Nature 520, 349-352. doi: 10.1038 /nature 14108

Ono, K., Toyono, T., and Inenaga, K. (2008). Nicotinic receptor subtypes in rat subfornical organ neurons and glial cells. Neuroscience 154, 994-1001. doi: 10.1016/j.neuroscience.2008.04.028

Phillips, R. S. (2002). How does active site water affect enzymatic stereo recognition? J. Mol. Cat. B. 19-20, 103-107. doi: 10.1016/S1381$1177(02) 00156-\mathrm{X}$

Picciotto, M. R., and Zoli, M. (2002). Nicotinic receptors in aging and dementia. J. Neurobiol. 53, 641-655. doi: 10.1002/neu.10102

Pretorius, R. W., Gataric, G., Swedlund, S. K., and Miller, J. R. (2013). Reducing the risk of adverse drug events in older adults. Am. Fam. Physician. 87, 331-336.

Qi, H., Qiu, X., Wang, C., Gaoa, Q., and Zhang, C. (2013). Digital electrogenerated chemiluminescence biosensor for the determination of multiple proteins based on Boolean logic gate. Anal. Methods 5, 612-615. doi: 10.1039/c2ay26054a

Reyes-Haro, D., Labrada-Moncada, F. E., Miledi, R., and Martínez-Torres, A. (2015). Dehydration-induced anorexia reduces astrocyte density in the rat corpus callosum. Neural Plast. 2015:474917. doi: 10.1155/2015/474917

Riebl, S. K., and Davy, B. M. (2013). The hydration equation: update on water balance and cognitive performance. ACSM's Health Fit. J. 17, 21-28. doi: 10.1249/FIT.0b013e3182a9570f

Rodríguez-Arellano, J. J., Parpura, V., Zorec, R., and Verkhratsky, A. (2016). Astrocytes in physiological aging and Alzheimer's disease. Neuroscience 323 , 170-182. doi: 10.1016/j.neuroscience.2015.01.007

Saji, E., Arakawa, M., Yanagawa, K., Toyoshima, Y., Yokoseki, A., Okamoto, K. et al. (2013). Cognitive impairment and cortical degeneration in neuromyelitis optica. Ann. Neurol. 73, 65-76. doi: 10.1002/ana.23721

Salminen, A., Ojala, J., Kaarniranta, K., Haapasalo, A., Hiltunen, M., and Soininen, H. (2011). Astrocytes in the aging brain express characteristics of senescenceassociated secretory phenotype. Eur. J. Neurosci. 34, 3-11. doi: 10.1111/j.14609568.2011.07738.x

Schlanger, L. E., Bailey, J. L., and Sands, J. M. (2010). Electrolytes in the aging. Adv. Chronic Kidney Dis. 17, 308-319. doi: 10.1053/j.ackd.2010.03.008

Sen, S., and Voorheis, H. P. (2014). Protein folding: understanding the role of water and the low Reynolds number environment as the peptide chain emerges from the ribosome and folds. J. Theor. Biol. 363, 169-187. doi: 10.1016/j.jtbi.2014.07.025

Sfera, A., and Osorio, C. (2014). Water for thought: is there a role for aquaporin channels in delirium? Front. Psychiatry 5:57. doi: 10.3389/fpsyt.2014.00057

Smythies, J. (2015). On the possible role of protein vibrations in information processing in the brain: three Russian dolls. Front. Mol. Neurosci. 8:38. doi: 10.3389/fnmol.2015.00038

St. Hillaire, C., Vargas, D., Pardo, C. A., Gincel, D., Mann, J., Rothstein, J. D., et al. (2005). Aquaporin 4 is increased in association with human immunodeficiency virus dementia: implications for disease pathogenesis. J. Neurovirol. 11, 535-543. doi: 10.1080/13550280500385203

Stoppini, M., Obici, L., Lavatelli, F., Giorgetti, S., Marchese, L., Moratti, R., et al. (2009). Proteomics in protein misfolding diseases. Clin. Chem. Lab. Med. 47, 627-635. doi: 10.1515/CCLM.2009.164

Streitbürger, D.-P., Möller, H. E., Tittgemeyer, M., Hund-Georgiadis, M., Schroeter, M. L., and Mueller, K. (2012). Investigating structural brain changes of dehydration using voxel-based morphometry. PLOS ONE 7:e44195. doi: 10.1371/journal.pone.0044195

Subburaman, T. T., and Vanisree, A. J. (2011). Oxidative pathology and AQP4 mRNA expression in patients of Parkinson's disease in Tamil Nadu. Ann. Neurosci. 18, 109-112. doi: 10.5214/ans.0972.7531.1118306

Tait, M. J, Saadoun, S., Bell, B. A, and Papadopoulos, M. C. (2008). Water movements in the brain: role of aquaporins. Trends Neurosci. 31, 37-43. doi: 10.1016/j.tins.2007.11.003

Tanaka, J. (2003). Activation of cholinergic pathways from the septum to the subfornical organ area under hypovolemic condition in 
rats. Brain Res. Bull. 61, 497-504. doi: 10.1016/S0361-9230(03) 00186-2

Tanaka, M., Tanaka, K., Komori, M., and Saida, T. (2007). Anti-aquaporin 4 antibody in Japanese multiple sclerosis: the presence of optic spinal multiple sclerosis without long spinal cord lesions and anti-aquaporin 4 antibody. J. Neurol. Neurosurg. Psychiatry 78, 990-992. doi: 10.1136/jnnp.2006. 114165

Thrane, A. S., Thrane, V. R., and Nedergaard, M. (2014). Drowning stars: reassessing the role of astrocytes in brain edema. Trends Neurosci. 37, 620-628. doi: 10.1016/j.tins.2014.08.010

Tokuriki, N., Kinjo, M., Negi, S., Hoshino, M., Goto, Y., Urabe, I., et al. (2004). Protein folding by the effects of macromolecular crowding. Protein Sci. 13, 125-133. doi: 10.1110/ps.03288104

Trinh-Trang-Tan, M. M., Geelen, G., Teillet, L., and Corman, B. (2003). Urea transporter expression in aging kidney and brain during dehydration. Am. J. Physiol. Regul. Integr. Comp. Physiol. 285, R1355-R1365. doi: 10.1152/ajpregu.00207.2003

Utsugisawa, K., Nagane, Y., Tohgi, H., Yoshimura, M., Ohba, H., and Genda, Y. (1999). Changes with aging and ischemia in nicotinic acetylcholine receptor subunit alpha7 mRNA expression in postmortem human frontal cortex and putamen. Neurosci. Lett. 270, 145-148. doi: 10.1016/S0304-3940(99)00473-5

Vajda, T., and Perczel, A. (2014). Role of water in protein folding, oligomerization, amyloidosis and miniprotein. J. Pept. Sci. 20, 747-759. doi: 10.1002/psc.2671

Wang, B. F., Cui, Z. W., Zhong, Z. H., Sun, Y. H., Sun, Q. F., Yang, G. Y., et al. (2015). Curcumin attenuates brain edema in mice with intracerebral hemorrhage through inhibition of AQP4 and AQP9 expression. Acta Pharmacol. Sin. 36, 939-948. doi: 10.1038/aps.2015.47

Warren, J. L., Bacon, W. E., Harris, T., McBean, A. M., Foley, D. J., and Phillips, C. (1994). The burden and outcomes associated with dehydration among US elderly, 1991. Am. J. Public Health. 84, 1265-1269. doi: 10.2105/AJPH.84. 8.1265

Xiao, H., Barber, J., and Campbell, E. S. (2004). Economic burden of dehydration among hospitalized elderly patients. Am. J. Health Syst. Pharm. 61, 2534-2540.
Xie, L., Kang, H., Xu, Q., Chen, M. J., Liao, Y., Thiyagarajan, M., et al. (2013). Sleep drives metabolite clearance from the adult brain. Science 342, 373-377. doi: $10.1126 /$ science. 1241224

Yang, M., Gao, F., Liu, H., Yu, W. H., Zhuo, F., Qiu, G. P., et al. (2013). Hyperosmotic induction of aquaporin expression in rat astrocytes through a different MAPK pathway. J. Cell Biochem. 114, 111-119. doi: 10.1002/jcb.24308

Yerbury, J. J., Stewart, E. M., Wyatt, A. R., and Wilson, M. R. (2005). Quality control of protein folding in extracellular space. EMBO Rep. 6, 1131-1136. doi: 10.1038/sj.embor.7400586

Zador, Z., Stiver, S., Wang, V., and Manley, G. T. (2009). Role of aquaporin-4 in cerebral edema and stroke. Handb. Exp. Pharmacol. 159-170. doi: 10.1007/9783-540-79885-9_7

Zhang, J., Yang, B., Sun, H., Zhou, Y., Liu, M., Ding, J., et al. (2016). Aquaporin-4 deficiency diminishes the differential degeneration of midbrain dopaminergic neurons in experimental Parkinson's disease. Neurosci. Lett. 614, 7-15. doi: 10.1016/j.neulet.2015.12.057

Zhang, N., Li, Y. J., Fu, Y., Shao, J. H., Luo, L. L., Yang, L., et al. (2015). Cognitive impairment in Chinese neuromyelitis optica. Mult. Scler. 21, 1839-1846. doi: $10.1177 / 1352458515576982$

Zhao, L., Li, W., and Tian, P. (2013). Reconciling mediating and slaving roles of water in protein conformational dynamics. PLOS ONE 8:e60553. doi: 10.1371/journal.pone.0060553

Conflict of Interest Statement: The authors declare that the research was conducted in the absence of any commercial or financial relationships that could be construed as a potential conflict of interest.

Copyright (c) 2016 Sfera, Cummings and Osorio. This is an open-access article distributed under the terms of the Creative Commons Attribution License (CC $B Y)$. The use, distribution or reproduction in other forums is permitted, provided the original author(s) or licensor are credited and that the original publication in this journal is cited, in accordance with accepted academic practice. No use, distribution or reproduction is permitted which does not comply with these terms. 